\title{
Attenuating Hypoxia-Induced Apoptosis and Autophagy of Mesenchymal Stem Cells: the Potential of Sitagliptin in Stem Cell-Based Therapy
}

\author{
Xi-Mei Wang Yue-Jin Yang Yong-Jian Wu Qian Zhang Hai-Yan Qian \\ Department of Cardiology, State Key Labratory of Cardiovascular Disease, Fuwai Hospital, National \\ Centre for Cardiovascular Diseases, Chinese Academy of Medical Sciences and Peking Union Medical \\ College, Beijing, People's Republic of China
}

\section{Key Words}

Sitagliptin • Mesenchymal stem cell • Hypoxia • Apoptosis • Autophagy

\begin{abstract}
Background/Aims: Dipeptidyl peptidase-4 (DPP-4) inhibitors have pleiotropic effects on cardiovascular protection beyond the antidiabetic property. However, it remains unknown that the impact of one DPP-4 inhibitor sitagliptin on the survival of mesenchymal stem cells (MSCs) in hypoxia and serum deprivation (H/SD) environment. Methods: The apoptosis and autophagy of MSCs were analyzed in different concentrations of sitagliptin under H/SD condition. For later studies, we tested the relationship between anti-apoptotic and anti-autophagic effects of sitagliptin. The level of cell apoptosis was analyzed by Annexin V-FITC/PI staining, western blot of Bcl-2 and Bax proteins. Autophagy flux was assessed by multiple autophagy related proteins and substrates. Cell autophagy was identified by acridine orange staining, western blot of Beclin 1 and light chain 3 protein, and transmission electron microscopy. Results: We demonstrated that sitagliptin attenuated hypoxia-induced apoptosis and autophagy of MSCs. Furthermore, sitagliptin regulated cell autophagy by Bcl-2/ Beclin 1 pathway in $\mathrm{H} / \mathrm{SD}$ condition. Conclusions: This study provides insight into the utility of the DPP-4 inhibitor sitagliptin for MSCs transplantation in the ischemic microenvironment that extends its antidiabetic property.
\end{abstract}

\section{Introduction}

Acute myocardial infarction is still a leading cause of morbidity and mortality worldwide. Many therapeutic strategies of pharmacologic intervention, percutaneous coronary intervention, and coronary artery bypass grafting can restore the blood flow 


\section{Cellular Physiology Cell Physiol Biochem 2015;37:1914-1926 and Biochemistry Published online: November 17, 2015 www.karger.com/cpb \\ Wang et al.: Sitagliptin Protectes Mesenchymal Stem Cells From Hypoxia}

and keep the viable myocardium working. In recent years, mesenchymal stem cell (MSC) transplantation has been a promising therapy strategy for cardiac repair after myocardium infarction. However, low survival of MSCs in the ischemic microenvironment limits clinical application. Therefore, increasing the survival of MSCs in ischemic microenvironment seems to be important.

Currently, the dipeptidyl peptidase-4 (DPP-4) inhibitors, a new class of oral antihyperglycemic agents, were found to have pleiotropic effects on cardiovascular protection beyond their antidiabetic property [1,2]. A previous study showed that the DPP-4 inhibitor sitagliptin upregulated the expression of the myocardial prosurvival kinase AKT and improved cardiac functional recovery after ischemia/reperfusion injury [3]. In addition, sitagliptin could reduce myocardial infarct size by cAMP-dependent PKA activation [4]. Systemic pretreatment with the DPP-4 inhibitor enhanced MSCs recruitment into ischemic myocardium, thereby leading to improve local vascularity and reverse myocardial remodeling [5]. Recently, it was showed that sitagliptin increased the amount of MSCs in the circulation and cardiac homing of bone-marrow derived stem cells [6]. However, the impact of the DPP4 inhibitor sitagliptin on the survival of MSCs in H/SD condition remains unclear.

In the past few decades, the relationship between apoptosis and autophagy-related cell death had attracted increasing attention in many fields of biological science. It is wellknown that both of them are important in the normal physiological and pathological state. There is a crosstalk between apoptosis and autophagy complex in nature, and sometimes contradictory, which is critical to the overall fate of the cells [7]. Autophagy can provide energy and metabolic precursors and alleviate stress by removal of damaged proteins and organelles under nutrient-limiting conditions [8,9]. Paradoxically, prolonged persistent autophagy as a stress response could lead to cell death [10]. Thus, autophagy can either protect cells or promote cell death, depending on the cellular and environmental context $[7,11]$. Despite the marked differences between apoptosis and autophagy, their regulation is intimately connected [10]. The same regulator Bcl-2, an anti-apoptotic protein, has been shown to reduce the pro-autophagic activity of Beclin $1[12,13]$ by the mechanism that Bcl2 interferes with the functions of Beclin 1 [14]. The effect of sitagliptin on apoptosis and autophagy of MSCs in H/SD condition will be studied in our experiment.

In this study, we first explored whether sitagliptin protected MSCs from apoptosis and autophagy in H/SD condition. Moreover, we investigated the relationship between apoptosis and autophagy in sitagliptin-induced protective effects.

\section{Materials and Methods}

\section{Cell culture and treatments}

MSCs were isolated from male Sprague-Dawley rats weighing 60-80g. Isolation of rat MSCs was performed according to the previous study [15]. Briefly, bone marrow was harvested from the femurs of the rats and seeded into cell culture flasks with complete medium (low-glucose DMEM, 10\% FBS [Invitrogen] and $1 \%$ penicillin-streptomycin [Invitrogen]) at $37^{\circ} \mathrm{C}$ in a humidified atmosphere containing $5 \% \mathrm{CO}_{2}$ and $95 \%$ air. When the cells reached $80 \%$ confluence, they were detached using $0.25 \%$ trypsin-EDTA (Invitrogen) and subcultured at the ratio of 1:2. Only the adherent cells were selected by this expansion protocol. Nonadherent hematopoietic cells decreased with consecutive passages. The passage 3 cells were used in each experiment.

The sitagliptin stock solution was prepared in DMSO and diluted with culture medium prior to the experiment. Previous studies showed that the early apoptosis and autophagy of MSCs induced by H/SD peaked at 6 hour $[15,16]$, so we adopted H/SD for 6 hours as the time point to observe the effects of sitagliptin on MSCs. The cells were washed in PBS and exposed to different concentrations of sitagliptin $(0.001 \mu \mathrm{M}, 0.01 \mu \mathrm{M}, 0.1 \mu \mathrm{M}, 1 \mu \mathrm{M}$ and $10 \mu \mathrm{M})$ in serum-free medium, and then incubated in a sealed, hypoxic GENbox jar fitted with a catalyst (Bio-Merieux) to scavenge free oxygen for 6 hours. The oxygen tension in the medium was measured by an anaerobic indicator (Bio-Mrieux). 


\section{Cellular Physiology Cell Physiol Biochem 2015;37:1914-1926 \begin{tabular}{l|l|l}
\cline { 2 - 3 } DOI: 10.1159/000438552 & ( ) 2015 The Author(s). Published by S. Karger AG, Basel
\end{tabular} and Biochemistry Published online: November 17, 2015 www.karger.com/cpb \\ Wang et al.: Sitagliptin Protectes Mesenchymal Stem Cells From Hypoxia}

Analysis of cell apoptosis by Annexin V-FITC/PI (Propidium Iodide) staining

Cell apoptosis was assessed by Annexin V-FITC/PI staining. Briefly, cells were collected and resuspended in $200 \mu \mathrm{L}$ medium buffer. $10 \mu \mathrm{L}$ of Annexin V solution was added to the cell suspending solution and incubated for $15 \mathrm{~min}$ avoiding light at room temperature. Then, $300 \mu \mathrm{L}$ medium buffer and 5 $\mu \mathrm{L}$ of PI were added and the cell suspension was analyzed by the flow cytometric machine immediately. In this study, Annexin V- /PI- cells represented viable cells, Annexin V+ /PI- cells represented early apoptotic cells, and PI + cells represented apoptotic or necrotic cells in terminal stages. $10^{4}$ cells were acquired on the flow cytometer (Becton-Dickinson, San Jose, CA) and analyzed by the FlowJo software.

\section{Measurement of cell autophagy by acridine orange (AO) staining}

We used AO staining for detection and quantification of acidic vesicular organelles (AVO) in autophagic cells [16]. Briefly, cells were collected and stained with $1 \mu \mathrm{g} / \mathrm{mL}$ AO for $15 \mathrm{~min}$. In the AO-stained cells, the cytoplasm fluoresce bright green and the acidic vesicular organelles fluoresce bright red. Green (510-530 $\mathrm{nm}$ ) and red (650 nm) fluorescence emission from $10^{4}$ cells illuminated with blue (488 nm) excitation light were measured on the flow cytometer (Becton-Dickinson, San Jose, CA). These data were analyzed by the FlowJo software.

\section{Western blot analysis}

Cells were homogenized in lysis buffer containing $50 \mathrm{mmol} / \mathrm{L}$ Tris- $\mathrm{HCl}$ (pH 7.3), $150 \mathrm{mmol} / \mathrm{L} \mathrm{NaCl}, 5$ mmol/L EDTA, $1 \mathrm{mmol} / \mathrm{L}$ dithiothreitol, 1\% Triton X-100, and 1\% protease inhibitor cocktail. The lysates were centrifuged (15 min at 12,000×g), and the supernatant was transferred to new tubes and stored at $-80^{\circ} \mathrm{C}$. Protein concentrations were quantified by BCA protein assay kit. The proteins were separated by SDS-PAGE electrophoresis and transferred to nitrocellulose membranes (Whatman) using a semi-dry electroblotting apparatus (Bio-Rad). The membranes were blocked for 1 hour at room temperature in 5\% skim milk, and then incubated overnight at $4^{\circ} \mathrm{C}$ with primary antibodies for $\beta$-actin $(1: 1000$, Cell Signaling Company, USA), Beclin1 (1:1000, Cell Signaling Company, USA)), light chain 3 (LC3) (1:300, Cell Signaling Company, USA), P62((1:1000, Cell Signaling Company, USA), Bax (1:500, Cell Signaling Company, USA), Bcl-2 (1:500, Cell Signaling Company, USA). The blots were washed with TBST, probed with the secondary antibody (1:5000, Zhongshan Company, China) at room temperature for 1 hour and again washed with TBST. The protein bands were detected by Chemiluminescence Detection Kit (Pierce) and quantified by the Quantity One software package (Bio-Rad Laboratories, UK).

\section{Detection of autophagosome by transmission electron microscopy}

To further clarify the effects of sitagliptin on cell autophagy, transmission electron microscopy, the standard method to detect autophagy was used. The collected cells were fixed with $2.5 \%$ glutaraldehyde in $0.1 \mathrm{~mol} / \mathrm{l}$ phosphatebuffer at $4^{\circ} \mathrm{C}$ for 2 hours, and post-fixed in $1 \%$ osmic acid at $4^{\circ} \mathrm{C}$ for 1.5 hours. After being washed with PBS, cells were then dehydrated by a serial gradient ethanol and then embedded in Embed-812 medium (Electron Microscopy Sciences). The blocks were cut into ultrathin sections using an Ultrotome (Leica, Reichert Ultracuts), which were then stained with $0.2 \%$ lead citrate/ $1 \%$ uranyl acetate. The ultrastructure of the cells was then observed under a transmission electron microscope (JEM1230; JEOL, Japan).

\section{Immunoprecipitation}

Protein concentration was quantified by bicinchoninic acid assay. Protein $(250 \mu \mathrm{g})$ was taken and antibodies $(2.5 \mu \mathrm{g} / \mathrm{mL})$ were incubated for 2 hours at $4{ }^{\circ} \mathrm{C}$ with protein G-conjugated agarose beads $(30 \mu \mathrm{L})$ and then washed 5 times with lysis buffer. To immunoprecipitate endogenous Bcl-2 and Beclin 1, anti-Beclin 1 immunoprecipitates were subjected to SDS-PAGE and Bcl-2 was analyzed by immunoblot analysis.

\section{Gene Silencing with Small Interfering RNA}

SignalSilence Control small interfering RNA (siRNA) and SignalSilence Bcl-2 siRNA were purchased from the company of Cell Signaling Technology. The siRNA transfection was performed using FuGENETM HD (Roche) according to the manufacturer's protocol. 


\section{Cellular Physiology Cell Physiol Biochem 2015;37:1914-1926 \begin{tabular}{cc|c|c|} 
DOI: $10.1159 / 000438552$ & O 2015 The Author(s). Published by S. Karger AG, Basel \\
and Biochemistry Published online: November 17, 2015 & www.karger.com/cpb
\end{tabular} \\ Wang et al.: Sitagliptin Protectes Mesenchymal Stem Cells From Hypoxia}

\section{Statistical analysis}

All values were expressed as the mean \pm SD. Comparison between 2 groups was evaluated by a Student's t test. Comparisons among 3 groups were conducted by one-way analysis of variance followed by. Least-Significant-Difference Post hoc test for multiple comparisons (SPSS 17.0 software). P $<0.05$ was considered to be statistically significant.

\section{Results}

Sitagliptin reduced apoptosis of MSCS under H/SD condition

The MSCs were exposed to the H/SD condition with different concentrations of sitagliptin $(0.001 \mu \mathrm{M}, 0.01 \mu \mathrm{M}, 0.1 \mu \mathrm{M}, 1 \mu \mathrm{M}$, and $10 \mu \mathrm{M})$ for 6 hours. The apoptosis of MSCs was tested by flow cytometric assay (Fig. 1A). The sitagliptin-treated MSCs showed better survival than untreated MSCs in a dose-dependent manner. Meanwhile, we analyzed the Bax and Bcl-2 proteins by western blot to identify the anti-apoptotic effect of sitagliptin. Protein expression of Bcl-2 was obviously upregulated, which reached a maximum in 10 $\mu \mathrm{M}$ sitagliptin-treated group. On the contrary, the protein expression of Bax was gradually decreased as the concentrations of sitagliptin increased (Fig. 1B).

\section{Sitagliptin reduced autophagy of MSCs under H/SD condition}

To determine whether sitagliptin was able to modulate autophagy of MSCs, we treated MSCs with different concentrations of sitagliptin $(0.001 \mu \mathrm{M}, 0.01 \mu \mathrm{M}, 0.1 \mu \mathrm{M}, 1 \mu \mathrm{M}$, and $10 \mu \mathrm{M})$ and then exposed them to H/SD condition for 6 hours. Compared with the normal

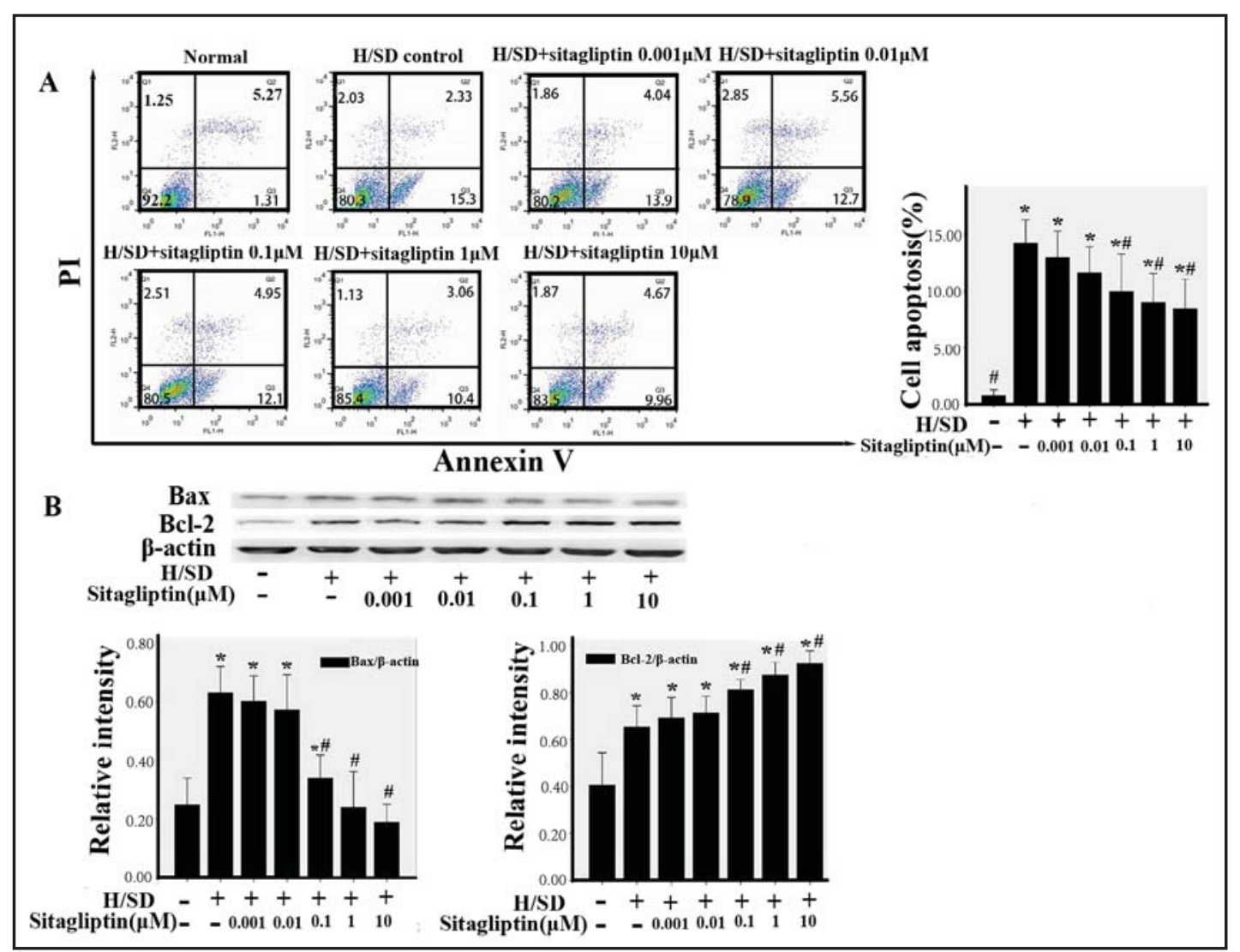

Fig. 1. Sitagliptin reduced apoptosis of MSCs under 6 hours of H/SD condition. (A) The early apoptotic cells were identified by Annexin V-FITC/PI staining(Error bars of standard deviation). (B) The expression levels of Bax and Bcl-2 were measured by western blot. The data represent the results of 3 separate experiments. ${ }^{*} \mathrm{P}<0.05$ (compared with the normal group); \# $<0.05$ (compared with the H/SD control group). 


\section{Cellular Physiology Cell Physiol Biochem 2015;37:1914-1926 \begin{tabular}{ll|l} 
and Biochemistry $10.1159 / 000438552$ & $\begin{array}{l}\text { () } 2015 \text { The Author(s). Published by S. Karger AG, Basel } \\
\text { www.karger.com/cpb }\end{array}$ \\
\cline { 1 - 3 }
\end{tabular}

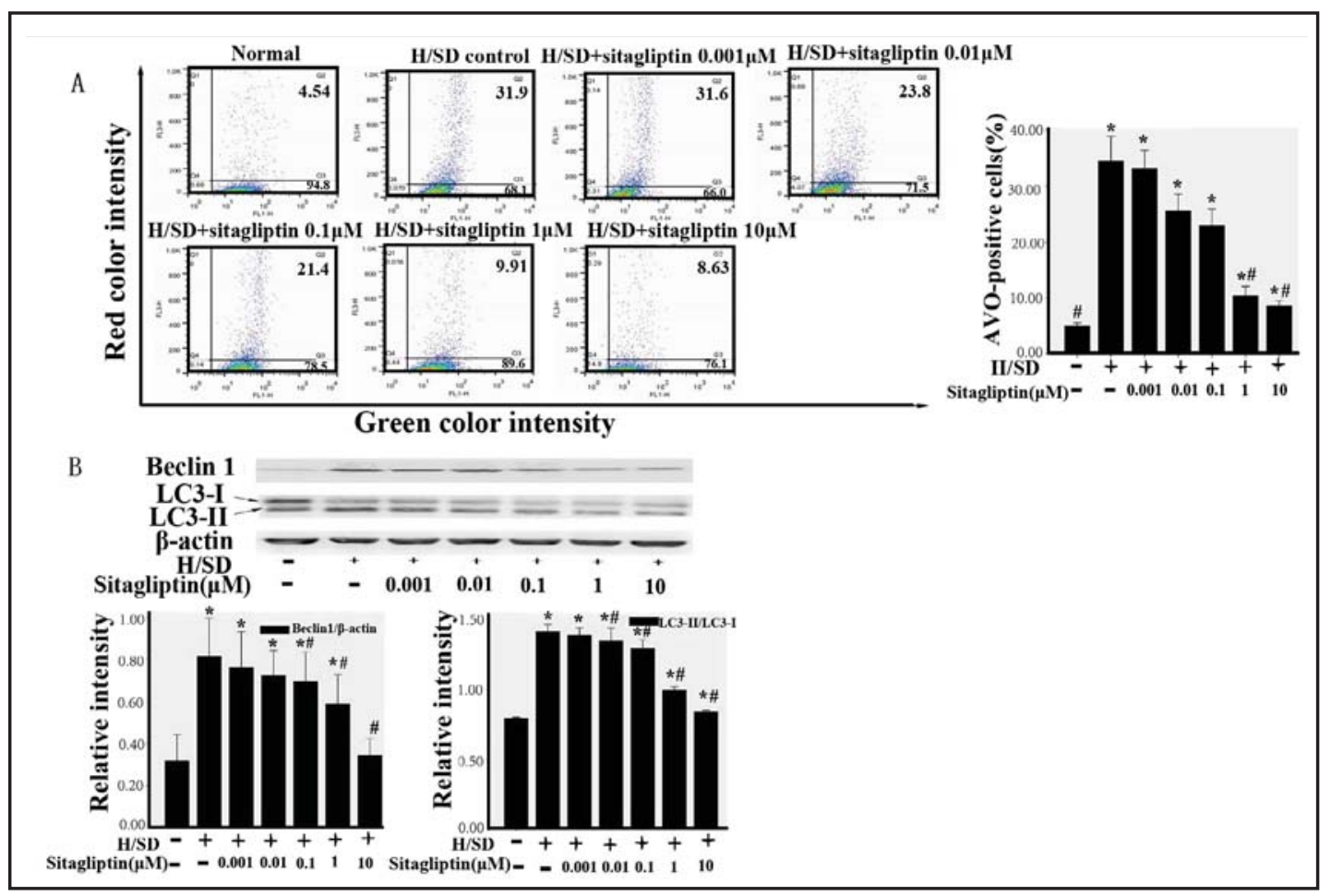

Fig. 2. Autophagic activity of MSCs was decreased by sitagliptin under H/SD condition. (A) Sitagliptin reduced H/SD-induced autophagy of MSCs, as indicated by AO staining. Quadrant 2 (Q2) in Fig. 2A indicated the double-membraned vacuoles digesting organelles or cytosolic contents. (B) The expression levels of Beclin 1 and LC3 were measured by western blot. The data represent the results of 3 separate experiments. ${ }^{*} \mathrm{P}<0.05$ (compared with the normal group); \#P $<0.05$ (compared with the H/SD control group). The data represent the results of 3 separate experiments. ${ }^{*} \mathrm{P}<0.05$ (compared with the non-sitagliptin group in 3 hours of H/SD); \#P < 0.05 (compared with the non-sitagliptin group in 6 hours of H/SD).

group, autophagic activity of MSCs was induced significantly in the H/SD control group ( the rate of AVO-positive cells $34.47 \pm 4.45 \%$ vs. $4.99 \pm 0.49 \%, \mathrm{P}=0.035$ ). As shown in Fig. $2 \mathrm{~A}$, the anti-autophagic effects of sitagliptin on MSCs were proved to be dose dependent. We also found that sitagliptin-treated MSCs showed lower LC3-II/LC3-I ratio than the control ones. Moreover, the expression of autophagic marker beclin 1 further demonstrated that sitagliptin could reduce the autophagy of MSCs (Fig. 2B). These results showed that compared to the $\mathrm{H} / \mathrm{SD}$ control group, sitagliptin-MSCs group had the lower level of cell autophagy $(\mathrm{P}<0.01)$.

The p62 protein is used as an indicator of autophagic degradation. It specifically interacts with LC3-II for its degradation by autophagolysosomes, and the cellular level of p62 is negatively correlated with autophagic flux. We assessed the autophagy flux of sitagliptintreated MSCs in 3 and 6 hours of H/SD condition. As shown in Fig. 3A, compared with the non-sitagliptin group, the LC3-II/LC3-I ratio was significantly decreased, and the p62 level were increased after sitagliptin treatment in both 3 hours and 6 hours of H/SD, indicating that autophagy inhibition by sitagliptin resulted in accumulation of p62. Following sitagliptin treatment, we further determined the level of LC3 isoforms, both in the presence and absence of bafilomycin A1 (Selleck, USA), an inhibitor of lysosomial degradation. Both 1 and $10 \mu \mathrm{M}$ sitagliptin induced a reduction of autophagic flux, suggesting the autophagy process was inhibited by sitagliptin (Fig. 3B).

\section{Sitagliptin regulated cell autophagy by Bcl-2/Beclin 1 pathway}

Sitagliptin attenuated apoptosis and autophagy of MSCs under H/SD condition in our study. However, whether there is a crosstalk between apoptosis and autophagy in these protective effects remains unclear. In the present study, the apoptotic rate of MSCs was found 


\section{Cellular Physiology Cell Physiol Biochem 2015;37:1914-1926

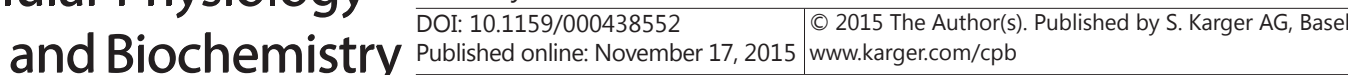

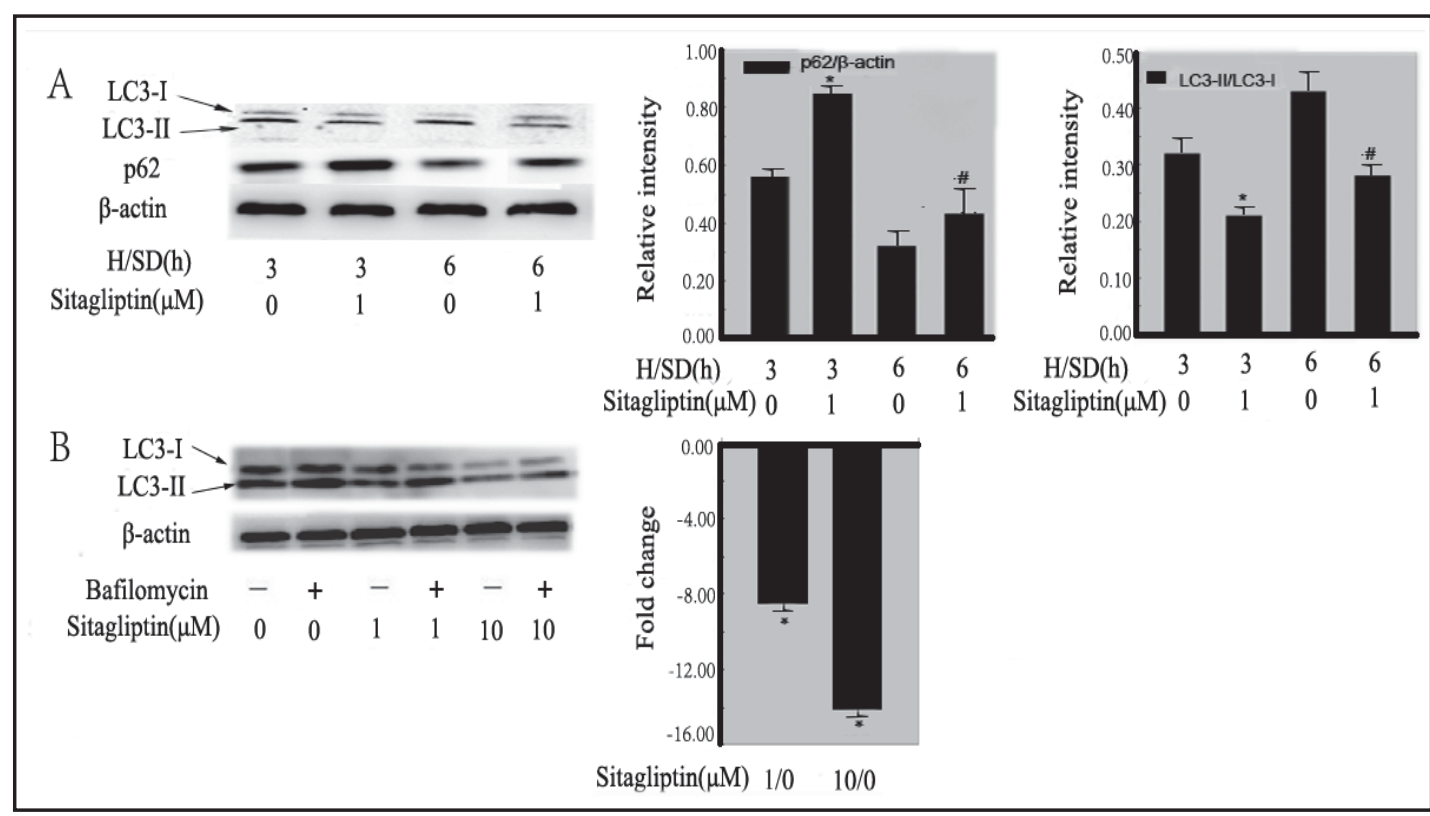

Fig. 3. The autophagy flux of MSCs treated by sitagliptin was assessed in H/SD condition. (A) The p62 levels of sitagliptin-treated MSCs were increased in both 3 and 6 hours of H/SD condition. (B) Both 1 and $10 \mu \mathrm{M}$ sitagliptin induced a reduction of autophagic flux. The cells were incubated for six hours and then harvested for western blot analysis. Two hours before the end of cell sample preparation, MSCs were incubated with $100 \mathrm{nM}$ Bafilomycin A1 or PBS to detect autophagic flux. We determined autophagic flux (AF) for LC3 II as follows: sitagliptin-treated MSCs AF=(sitagliptin-treated MSCs+Bafylomycin A1)- (sitagliptin-treated MSCs +PBS); Control MSCs AF = (Control MSCs + Bafylomycin A1) - (Control MSCs + PBS). Change in autophagic flux $(\triangle \mathrm{AF})$ between sitagliptin -treated and control MSCs was calculated as $\triangle \mathrm{AF}=$ sitagliptin-treated MSCs AF - Control MSCs AF. The graph shows AF changes in sitagliptin-treated MSCs compared to control cultures. Data are expressed in change folds $(n=3, * p<0.05)$.

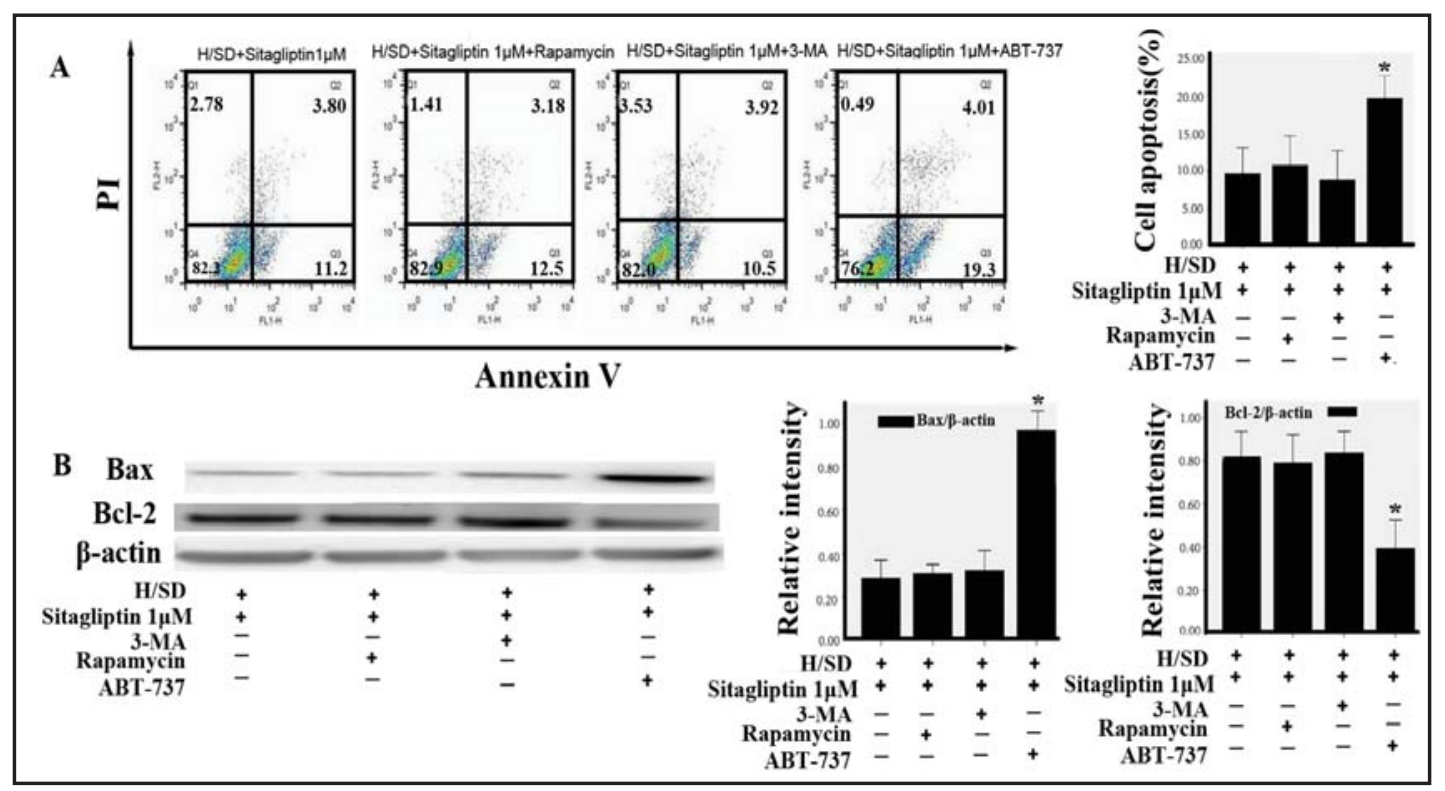

Fig. 4. The effects of 3-MA, rapamycin or ABT-737 on the apoptosis of $1 \mu \mathrm{M}$ sitagliptin-treated MSCs under H/SD condition. (A) The early apoptotic cells were assessed by Annexin V-FITC/PI staining. (B) The expression levels of Bax and Bcl-2 were measured by western blot. The results showed that 3-MA or rapamycin had no significant effects on cell apoptosis. However, ABT-737 significantly increased cell apoptosis. The data represent the results of 3 separate experiments. ${ }^{*} \mathrm{P}<0.05$ (compared with the $1 \mu \mathrm{M}$ sitagliptin group). 


\section{Cellular Physiology Cell Physiol Biochem 2015;37:1914-1926 \begin{tabular}{ll|l} 
and Biochemistry & $\begin{array}{l}\text { DOI: 10.1159/000438552 } \\
\text { Published online: November 17, } 2015\end{array}$ & $\begin{array}{l}\text { ○ } 2015 \text { The Author(s). Published by S. Karger AG, Basel } \\
\text { www.karger.com/cpb }\end{array}$ \\
\cline { 2 - 3 }
\end{tabular} \\ Wang et al.: Sitagliptin Protectes Mesenchymal Stem Cells From Hypoxia}

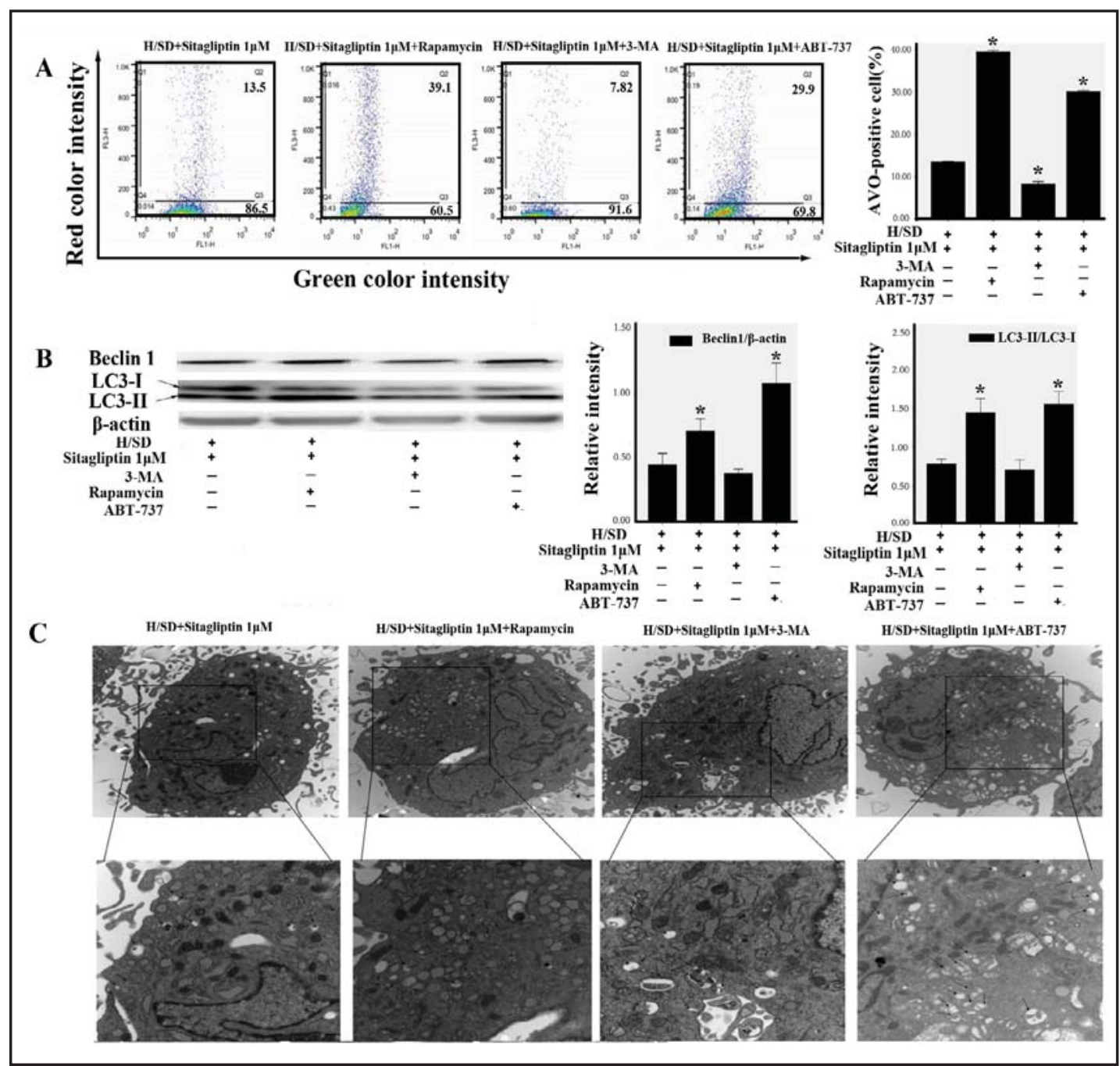

Fig. 5. ABT-737 increased autophagic activity of $1 \mu \mathrm{M}$ sitagliptin-treated MSCs under H/SD condition. (A) Cell autophagy was assessed by AO staining (Error bars of standard deviation). (B) Western blot was used to detect the expression of Beclin 1 and LC3 proteins. (C) Transmissionelectron microscopy was used to detect autophagic vacuole formation. The data represent the results of 3 separate experiments. ${ }^{*} \mathrm{P}<0.05$ (compared with the $1 \mu \mathrm{M}$ sitagliptin group).

to be positively correlated with the rate of AVO-positive MSCs in sitagliptin-treated groups under H/SD condition (Pearson correlation: $0.693, \mathrm{P}<0.001$ ). To further test the association of anti-apoptosis and anti-autophagy of sitagliptin, we exposed $1 \mu \mathrm{M}$ sitagliptin-treated MSCs with autophagy activator rapamycin, autophagy inhibitor 3-MA or Bcl-2 inhibitor ABT737 in H/SD condition for 6 hours. Then we assessed the apoptosis and autophagy of MSCs in each sample. As shown in Fig. 4A, rapamycin or 3-MA had no significant effects on the apoptosis of sitagliptin-treated MSCs as identified by the apoptotic rate $(10.72 \pm 1.59 \%$ vs. $9.62 \pm 1.38 \%, \mathrm{P}=0.379 ; 8.76 \pm 1.56 \%$ vs. $9.62 \pm 1.38 \%, \mathrm{P}=0.486$, compared with $1 \mu \mathrm{M}$ sitagliptin group). However, ABT-737 increased the apoptosis and autophagy of sitagliptintreated MSCs (Fig. 4A and Fig. 5A). Meanwhile, the western blot analysis showed that the protein expression of Bax and Bcl-2 was not influenced by rapamycin or 3-MA. However, ABT-737 which decreased the expression of Bcl-2 significantly increased the expression of Bax (Fig. 4B). The expression of Beclin 1, LC3-II/LC3-I ratio was significantly increased by ABT-737 (Fig. 5B). In addition, Fig. 5C further showed that autophagic vacuole formation increased in the ABT-737 group. 


\section{\begin{tabular}{ll} 
Cellular Physiology & Cell Physiol Biochem 2015;37:1914-1926 \\
\cline { 2 - 2 } DOI: 10.1159/000438552 & O 2015 The Author(s). Published by S. Karger AG, Basel
\end{tabular} \begin{tabular}{ll|l} 
DOI: 10.1159/000438552 & O 2015 The Author(s). Published by S. Karger AG, Basel \\
and Biochemistry Published online: November 17, 2015 & www.karger.com/cpb \\
\cline { 2 - 3 }
\end{tabular} \\ Wang et al.: Sitagliptin Protectes Mesenchymal Stem Cells From Hypoxia}

A

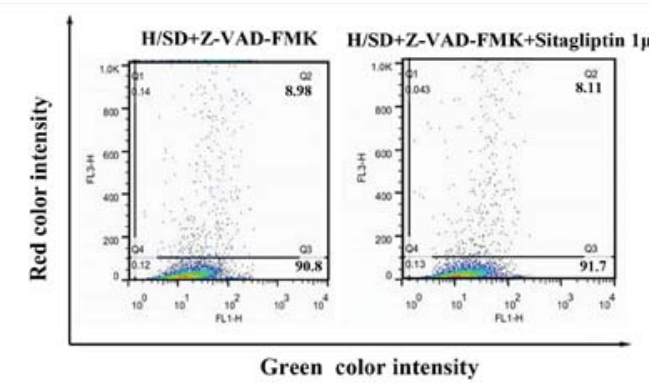

B

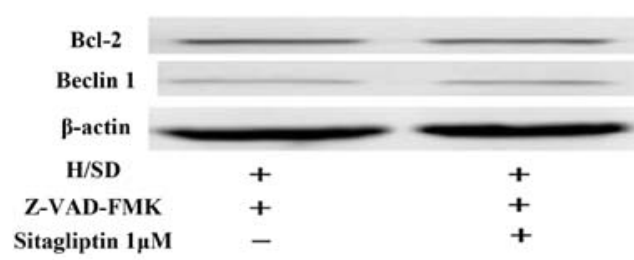

$\mathrm{C}$

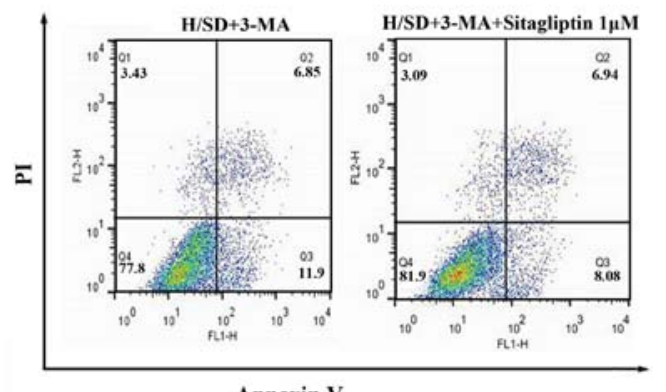

Annexin V

D

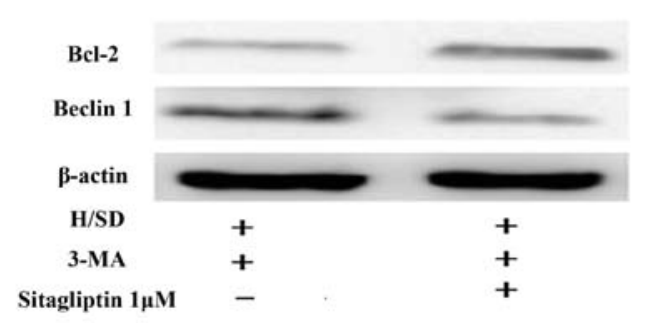

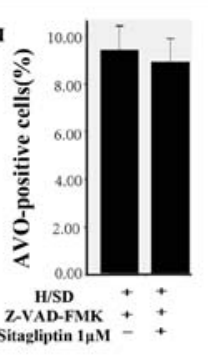

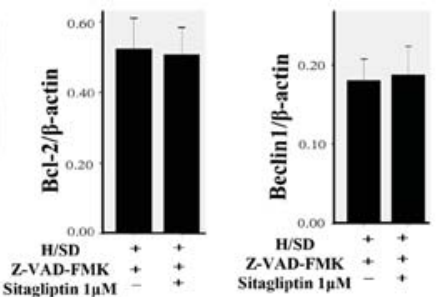

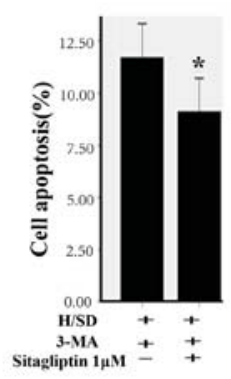
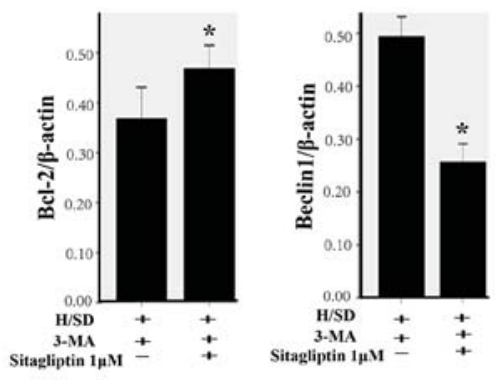

Fig. 6. The effects of sitagliptin on MSCs were assessed when the apoptotic or autophagic pathways were inhibited. (A) The effect of sitagliptin on cell autophagy was assessed by AO staining when apoptotic pathways were blocked by Z-VAD-FMK. (B) Western blot was used to detect the expression of Beclin 1 when apoptotic pathways were blocked by Z-VAD-FMK. (C) The effect of sitagliptin on cell apoptosis was assessed by Annexin V-FITC/PI staining when autophagic pathways were blocked by 3-MA. (D) Western blot was used to detect the expression of Bcl-2 when autophagic pathways were blocked by 3-MA. The data represent the results of 3 separate experiments. ${ }^{*} \mathrm{P}<0.05$ (compared with the H/SD+3-MA group).

To further determine whether sitagliptin regulated cell autophagy by some important molecules in its anti-apoptotic pathways, we conducted the apoptotic inhibitor Z-VAD-FMK $(20 \mu \mathrm{M})$ to block the apoptotic pathways, and then assessed the effects of sitagliptin on cell autophagy in H/SD condition. As shown in Fig. 6A, when the apoptotic pathways were blocked, sitagliptin did not further affect the autophagic activity of MSCs. Compared with Z-VAD-FMK control group, the expression of autophagic protein Beclin 1 had no obvious changes in Z-VAD-FMK+ sitagliptin group (Fig. 6B). In addition, the MSCs were first treated with the autophagic inhibitor 3-MA followed by sitagliptin in H/SD condition for 6 hours 


\section{Cellular Physiology Cell Physiol Biochem 2015;37:1914-1926

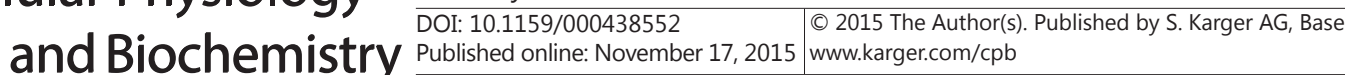

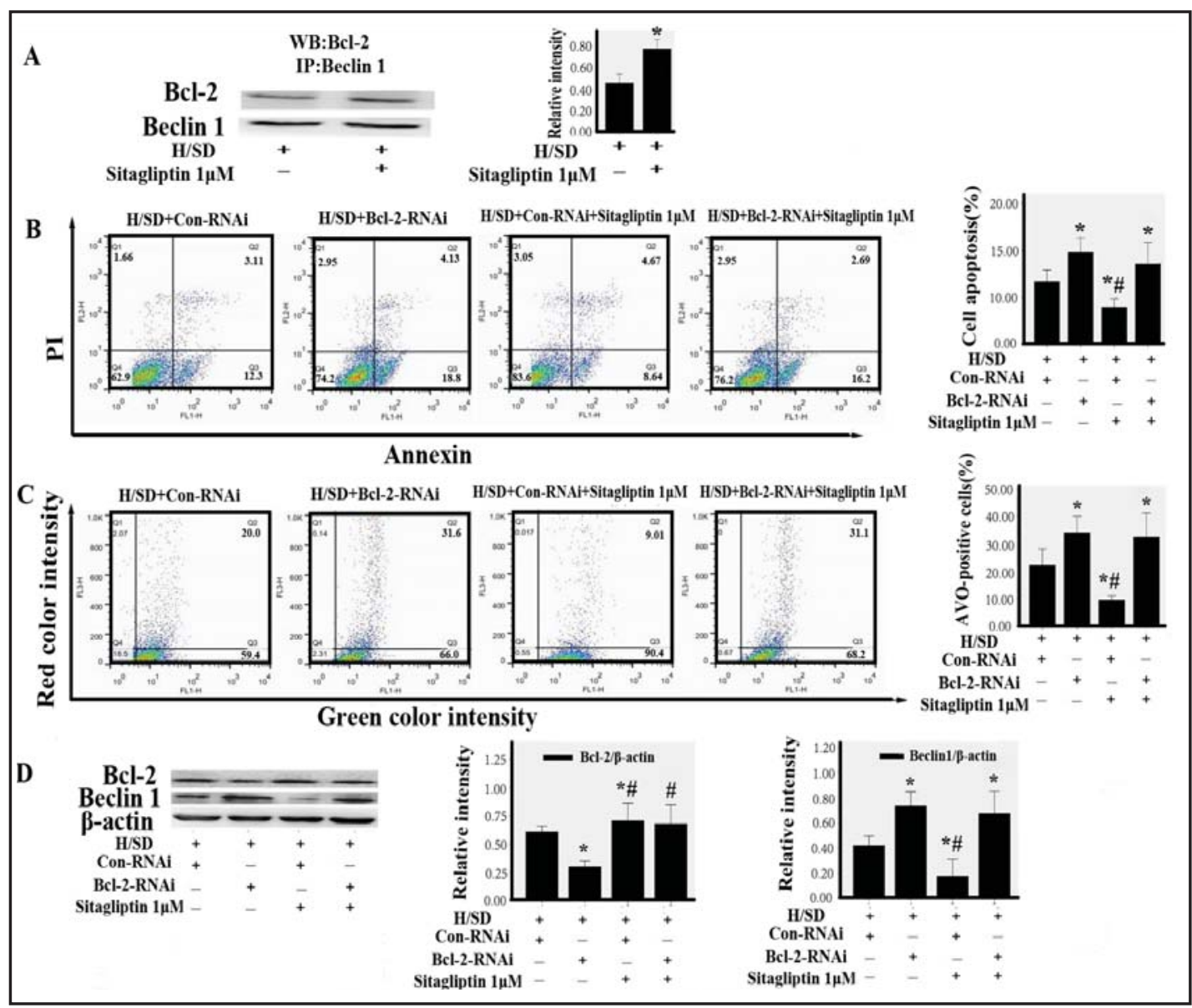

Fig. 7. The role of Bcl-2 in modulating both apoptosis and autophagy of MSCs. (A) The interaction between Bcl- 2 and Beclin 1 in the effects of sitagliptin. ${ }^{*} \mathrm{P}<0.05$ (compared with the H/SD control group). (B) The effect of sitagliptin on cell apoptosis was assessed by Annexin V-FITC/PI staining in MSCs with Bcl-2-RNAi. (C) The effect of sitagliptin on cell autophagy was assessed by AO staining in MSCs with Bcl-2-RNAi. (D) Western blot was used to detect the expression of Bcl-2 and Beclin 1 in MSCs with Bcl-2-RNAi. The data represent the results of 3 separate experiments. ${ }^{*} \mathrm{P}<0.05$ (compared with the $\mathrm{H} / \mathrm{SD}+\mathrm{Con}-\mathrm{RNAi}$ group in $\mathrm{B}, \mathrm{C}, \mathrm{D}$ ). $\# \mathrm{P}<0.05$ (compared with the H/SD+Bcl-2-RNAi group in $\mathrm{B}, \mathrm{C}, \mathrm{D}$ ).

to observe the effects of sitagliptin on cell apoptosis. Fig. 6C showed that sitagliptin could further attenuate the apoptotic rate of MSCs. And the expression of Bcl-2 increased in Fig. 6D.

To evaluate whether Bcl-2 played a role in the anti- autophagic effect of sitagliptin, we analyzed the interaction between Bcl-2 and Beclin 1 by coimmunoprecipitation assays. Compared with H/SD group, pretreatment with sitagliptin resulted in higher levels of Bcl2 coimmunoprecipitating with Beclin 1 (Fig. 7A). We used Bcl-2-RNA interference (RNAi) to decrease $\mathrm{Bcl}-2$ expression to test the role of $\mathrm{Bcl}-2$ in modulating both apoptosis and autophagy of MSCs. The MSCs were infected with Bcl-2-RNAi or scrambled control (CON)RNAi followed by treatment with sitagliptin. The results showed that Bcl-2 siRNA treatment markedly increased cell apoptosis and autophagy (Fig. 7B and C). When Bcl-2-RNAi blocked Bcl-2 expression, sitagliptin did not further attenuate cell apoptosis and autophagy. Meanwhile, the western blot was used to detect the expression of Bcl-2 and Beclin 1 in MSCs with Bcl-2-RNAi. The expression of Bcl-2 and Beclin 1 had no significant changes when Bcl-2 was blocked by Bcl-2-RNAi (Fig. 7D). All these data suggested that sitagliptin could regulate autophagic activity of MSCs by Bcl-2/ Beclin 1 pathway in H/SD condition. 


\section{Cellular Physiology Cell Physiol Biochem 2015;37:1914-1926 \begin{tabular}{ll|l} 
DOI: 10.1159/000438552 & $\begin{array}{l}\text { O 2015 The Author(s). Published by S. Karger AG, Basel } \\
\text { www.karger.com/cpb }\end{array}$ \\
\hline
\end{tabular} Wang et al.: Sitagliptin Protectes Mesenchymal Stem Cells From Hypoxia}

\section{Discussion}

In the present study, we found that sitagliptin attenuated hypoxia-induced apoptosis and autophagy of MSCs. Interestingly, sitagliptin regulated cell autophagy by Bcl-2/Beclin 1 pathway in H/SD condition. These results provide insight into the utility of sitagliptin for MSCs transplantation in the ischemic microenvironment that beyond its antidiabetic property.

As is known to all, the efficacy of MSCs transplantation is limited by the poor viability of MSCs when they were transplanted into myocardial necrosis area. It is demonstrated that many drugs such as statins or trimetazidine can protect MSCs against H/SD $[16,17]$. Moreover, the factors released by of MSCs could protect endothelial cells from serum deprivation [18]. DPP-4 inhibitors are a newer class of oral anti-hyperglycemic agents with demonstrated efficacy in the treatment of type 2 diabetes $[19,20]$. In recent years, DPP-4 inhibitors are demonstrated to mediate pleiotropic effects in cardiovascular protection. DPP4 inhibitors could decrease myocardial infarct size, stabilize the cardiac electrophysiological state, reduce ischemia/reperfusion injury, and prevent left ventricular remodeling following myocardial infarction [21-23]. However, it is unclear that whether sitagliptin could inhibit H/SD-induced apoptosis and autophagy of MSCs.

Our results showed that sitagliptin alone had protective effects against hypoxia injury in vitro, which is opposite to the study of Ye et al. [4]. Although many evidences indicated that GLP-1 had important cardiovascular actions, we did not observe an increase of GLP-1 after treatment with sitagliptin in $\mathrm{H} / \mathrm{SD}$ condition (data not shown). It might be that the protective mechanisms of sitagliptin for MSCs are different from those for the cardiomyocytes. In addition, not altered level of GLP-1 in the vitro model did not suggest that the protective effects of sitagliptin were GLP-1 receptor independent. Whether sitagliptin directly activates GLP-1 receptor is still unclear.

The p62 level of MSCs treated by sitagliptin was increased in both 3 hours and 6 hours of $\mathrm{H} / \mathrm{SD}$ condition, suggesting that autophagy inhibition by sitagliptin was associated with cell survival. Since the amount of LC3 at a certain time point does not indicate autophagic flux, we measured the amount of LC3-II in the presence and absence of lysosomal protease inhibitors to determine changes in autophagic flux $[24,25]$. The results showed that sitagliptin induced a reduction of autophagic flux, suggesting the autophagy process was indeed inhibited by sitagliptin.

However, sitagliptin did not further affect cell autophagy when the apoptotic pathways were blocked. Increasing or decreasing cell autophagy had no significant effects on the apoptosis of sitagliptin-treated MSCs, suggesting that sitagliptin regulated cell autophagy by some important molecules in apoptotic pathway. That is to say, autophagy inhibition by sitagliptin is secondary to its anti-apoptotic effects. Autophagy could serve as a pro-survival stress response in many settings. However, the role of autophagy in modulating cell death is highly dependent on the cellular context and its extent. In six hours of H/SD, the cells were put in a sealed, hypoxic GENbox jar fitted with a catalyst to scavenge free oxygen, which resulted in continuously decreasing oxygen levels until anoxia. Persistent autophagy responded to excessive stress. Autophagy may promote cell death through excessive self-digestion and degradation of essential cellular constituents [26]. Our results indicated that inhibiting autophagy was the downstream consequences of anti-apoptotic effects of sitagliptin, which further increased cell survival in H/SD condition. However, cell autophagy and senescence induced by stress are closely related but not necessarily interdependent responses. Their relationship is complex. Autophagy may promote or counteract senescence [27, 28]. Indeed, senescence could greatly affect the characteristics of cells $[29,30]$. It is not yet known that whether sitagliptin could inhibit H/SD-induced senescence of MSCs. The relationship between autophagy and senescence of MSCs treated by sitagliptin in H/SD condition needs further studies.

In this study, sitagliptin increased Bcl-2 expression which reduced levels of H/SDinduced autophagy. Furthermore, siRNA silencing of Bcl-2 in MSCs increased levels of H/SD- 


\section{Cellular Physiology Cell Physiol Biochem 2015;37:1914-1926 \begin{tabular}{ll|l} 
DOI: 10.1159/000438552 & $\begin{array}{l}\text { O 2015 The Author(s). Published by S. Karger AG, Basel } \\
\text { www.karger.com/cpb }\end{array}$ \\
\hline
\end{tabular} Wang et al.: Sitagliptin Protectes Mesenchymal Stem Cells From Hypoxia}

induced autophagy, suggesting that Bcl-2 played an important role in the regulation of cell autophagy. As we know, Bcl-2 could regulate the mitochondrial response to cell death stimuli $[31,32]$. Recently, Bcl-2 was found to be involved in autophagy inhibition [12, 33]. Bcl-2 could block autophagic cell death by binding to Beclin 1 [34]. Our data showed that the interaction between Bcl-2 and Beclin 1 can be mediated by sitagliptin. One possible explanation of these findings was that cellular Bcl-2 protein could inhibit autophagy by interaction with Beclin 1 . The relative amount of Bcl- 2 and Beclin 1 complexed to each other within a cell determines the level of autophagy and autophagic cell death. The interaction between endogenous Bcl2 and Beclin 1 is regulated by nutrient conditions. Bcl-2 binding to Beclin 1 is minimal in nutrient deprivation [13], and the level of cell autophagy is raised. In addition, Beclin 1 could promote cell autophagy [35]. And cells with reduced Beclin 1 expression exhibited reduced autophagic activity $[36,37]$. Taken together, these results jointly suggested that autophagy could be regulated by sitagliptin through Bcl-2/ Beclin 1 pathway in H/SD condition.

In summary, sitagliptin could attenuate H/SD-induced apoptosis and autophagy of MSCs in a dose-dependent manner. Furthermore, sitagliptin could regulate autophagy of MSCs by Bcl-2/ Beclin 1 pathway in H/SD condition.

However, there are still some limitations in our study. First, the effects of Bcl-2 may associate with their subcellular localization $[13,38]$. However, we did not distinguish mitochondrial-targeted Bcl-2 or endoplasmic reticulum-targeted Bcl-2 in this study. Second, reactive oxygen species(ROS) are important signaling molecules that initiate cell apoptosis and autophagy [39]. Whether redox regulates the structure and function of Bcl-2 and Beclin 1 is unclear. Finally, we did not assess the efficacy of sitagliptin-treated MSCs in animal models. These issues will be resolved in future experiments.

\section{Acknowledgements}

We thank Li Song and Jue Ye of core laboratory for technical assistance. This work was supported by grants from China Health \& Medical Development Foundation (2011-H25 to Y.J. Yang).

\section{Disclosure Statement}

None.

\section{References}

1 Murohara T: Dipeptidyl peptidase-4 inhibitor: another player for cardiovascular protection. J Am Coll Cardiol 2012;59:277-279.

2 Fadini GP, Avogaro A: Cardiovascular effects of dpp-4 inhibition: beyond glp-1. Vascul Pharmacol 2011;55:10-16.

3 Sauve M, Ban K, Momen MA, Zhou YQ Henkelman RM, Husain M, Drucker DJ: Genetic deletion or pharmacological inhibition of dipeptidyl peptidase-4 improves cardiovascular outcomes after myocardial infarction in mice. Diabetes 2010;59:1063-1073.

4 Ye Y, Keyes KT, Zhang C, Perez-Polo JR, Lin Y, Birnbaum Y: The myocardial infarct size-limiting effect of sitagliptin is pka-dependent, whereas the protective effect of pioglitazone is partially dependent on pka. Am J Physiol Heart Circ Physiol 2010;298:H1454-H1465.

5 Zhang D, Huang W, Dai B, Zhao T, Ashraf A, Millard RW, Ashraf M, Wang Y: Genetically manipulated progenitor cell sheet with diprotin a improves myocardial function and repair of infarcted hearts. Am J Physiol Heart Circ Physiol 2010;299:H1339-H1347. 


\section{Cellular Physiology Cell Physiol Biochem 2015;37:1914-1926 \begin{tabular}{ll|l} 
aOI: 10.1159/000438552 & $\begin{array}{l}\text { @ 2015 The Author(s). Published by S. Karger AG, Basel } \\
\text { www.karger.com/cpb }\end{array}$ \\
\cline { 2 - 4 }
\end{tabular}}

Wang et al.: Sitagliptin Protectes Mesenchymal Stem Cells From Hypoxia

6 Theiss HD, Gross L, Vallaster M, David R, Brunner S, Brenner C, Nathan P, Assmann G, Mueller-Hoecker J, Vogeser M, Steinbeck G, Franz WM: Antidiabetic gliptins in combination with g-csf enhances myocardial function and survival after acute myocardial infarction. Int J Cardiol 2013;168:3359-3369.

7 Eisenberg-Lerner A, Bialik S, Simon HU, Kimchi A: Life and death partners: apoptosis, autophagy and the cross-talk between them. Cell Death Differ 2009;16:966-975.

8 Levine B, Klionsky DJ: Development by self-digestion: molecular mechanisms and biological functions of autophagy. Dev Cell 2004;6:463-477.

9 Cecconi F, Levine B: The role of autophagy in mammalian development: cell makeover rather than cell death. Dev Cell 2008;15:344-357.

10 Thorburn A: Apoptosis and autophagy: regulatory connections between two supposedly different processes. Apoptosis 2008;13:1-9.

11 Codogno P, Meijer AJ: Autophagy and signaling: their role in cell survival and cell death. Cell Death Differ 2005;12 Suppl 2:1509-1518.

12 Maiuri MC, Le Toumelin G, Criollo A, Rain JC, Gautier F, Juin P, Tasdemir E, Pierron G, Troulinaki K, Tavernarakis N, Hickman JA, Geneste O, Kroemer G: Functional and physical interaction between bcl-x(l) and a bh3-like domain in beclin-1. Embo J 2007;26:2527-2539.

13 Pattingre S, Tassa A, Qu X, Garuti R, Liang XH, Mizushima N, Packer M, Schneider MD, Levine B: Bcl-2 antiapoptotic proteins inhibit beclin 1-dependent autophagy. Cell 2005;122:927-939.

14 Saeki K, Yuo A, Okuma E, Yazaki Y, Susin SA, Kroemer G, Takaku F: Bcl-2 down-regulation causes autophagy in a caspase-independent manner in human leukemic hl60 cells. Cell Death Differ 2000;7:1263-1269.

15 Zhu W, Chen J, Cong X, Hu S, Chen X: Hypoxia and serum deprivation-induced apoptosis in mesenchymal stem cells. Stem Cells 2006;24:416-425.

16 Zhang Q, Yang YJ, Wang H, Dong QT, Wang TJ, Qian HY, Xu H: Autophagy activation: a novel mechanism of atorvastatin to protect mesenchymal stem cells from hypoxia and serum deprivation via amp-activated protein kinase/mammalian target of rapamycin pathway. Stem Cells Dev 2012;21:1321-1332.

17 Gong X, Fan G, Wang W, Wang G: Trimetazidine protects umbilical cord mesenchymal stem cells against hypoxia and serum deprivation induced apoptosis by activation of akt. Cell Physiol Biochem 2014;34:2245-2255.

18 Bader AM, Brodarac A, Klose K, Bieback K, Choi YH, Kang KS, Kurtz A, Stamm C: Cord blood mesenchymal stromal cell-conditioned medium protects endothelial cells via stat3 signaling. Cell Physiol Biochem 2014;34:646-657.

19 Lasserson D, Mant J: The role of dipeptidyl peptidase-4 inhibitors. BMJ 2012;344:e1213.

20 Baetta R, Corsini A: Pharmacology of dipeptidyl peptidase-4 inhibitors: similarities and differences. Drugs 2011;71:1441-1467.

21 Jose T, Inzucchi SE: Cardiovascular effects of the dpp-4 inhibitors. Diab Vasc Dis Res 2012;9:109-116.

22 Dicker D: Dpp-4 inhibitors: impact on glycemic control and cardiovascular risk factors. Diabetes Care 2011;34:S276-S278.

23 Murohara T: Dipeptidyl peptidase-4 inhibitor: another player for cardiovascular protection. J Am Coll Cardiol 2012;59:277-279.

24 Alessio N, Del GS, Capasso S, Di Bernardo G, Cappabianca S, Cipollaro M, Peluso G, Galderisi U: Low dose radiation induced senescence of human mesenchymal stromal cells and impaired the autophagy process. Oncotarget 2015;6:8155-8166.

25 Klionsky DJ, Abeliovich H, Agostinis P, et al.: Guidelines for the use and interpretation of assays for monitoring autophagy in higher eukaryotes. Autophagy 2008;4:151-175.

26 Wen YD, Sheng R, Zhang LS, Han R, Zhang X, Zhang XD, Han F, Fukunaga K, Qin ZH: Neuronal injury in rat model of permanent focal cerebral ischemia is associated with activation of autophagic and lysosomal pathways. Autophagy 2008;4:762-769.

27 Gewirtz DA: Autophagy and senescence: a partnership in search of definition. Autophagy 2013;9:808-812.

28 White E, Lowe SW: Eating to exit: autophagy-enabled senescence revealed. Genes Dev 2009;23:784-787.

29 Squillaro T, Alessio N, Cipollaro M, Melone MA, Hayek G, Renieri A, Giordano A, Galderisi U: Reduced expression of mecp2 affects cell commitment and maintenance in neurons by triggering senescence: new perspective for rett syndrome. Mol Biol Cell 2012;23:1435-1445. 


\section{Cellular Physiology Cell Physiol Biochem 2015;37:1914-1926 \begin{tabular}{ll|l} 
DOI: 10.1159/000438552 & O 2015 The Author(s). Published by S. Karger AG, Basel \\
and Biochemistry Published online: November 17, 2015 & www.karger.com/cpb
\end{tabular} \\ Wang et al.: Sitagliptin Protectes Mesenchymal Stem Cells From Hypoxia}

30 Severino V, Alessio N, Farina A, Sandomenico A, Cipollaro M, Peluso G, Galderisi U, Chambery A: Insulinlike growth factor binding proteins 4 and 7 released by senescent cells promote premature senescence in mesenchymal stem cells. Cell Death Dis 2013;4:e911.

31 Youle RJ, Strasser A: The bcl-2 protein family: opposing activities that mediate cell death. Nat Rev Mol Cell Biol 2008;9:47-59.

32 Kroemer G, Galluzzi L, Brenner C: Mitochondrial membrane permeabilization in cell death. Physiol Rev 2007;87:99-163.

33 Danial NN, Korsmeyer SJ: Cell death: critical control points. Cell 2004;116:205-219.

34 Pattingre S, Levine B: Bcl-2 inhibition of autophagy: a new route to cancer? Cancer Res 2006;66:28852888.

35 Liang XH, Jackson S, Seaman M, Brown K, Kempkes B, Hibshoosh H, Levine B: Induction of autophagy and inhibition of tumorigenesis by beclin 1. Nature 1999;402:672-676.

36 Yue Z, Jin S, Yang C, Levine AJ, Heintz N: Beclin 1, an autophagy gene essential for early embryonic development, is a haploinsufficient tumor suppressor. Proc Natl Acad Sci U S A 2003;100:15077-15082.

37 Qu X, Yu J, Bhagat G, Furuya N, Hibshoosh H, Troxel A, Rosen J, Eskelinen EL, Mizushima N, Ohsumi Y, Cattoretti G, Levine B: Promotion of tumorigenesis by heterozygous disruption of the beclin 1 autophagy gene. J Clin Invest 2003;112:1809-1820.

38 Strappazzon F, Vietri-Rudan M, Campello S, Nazio F, Florenzano F, Fimia GM, Piacentini M, Levine B, Cecconi F: Mitochondrial bcl-2 inhibits ambra1-induced autophagy. Embo J 2011;30:1195-1208.

39 Navarro-Yepes J, Burns M, Anandhan A, Khalimonchuk O, Del RL, Quintanilla-Vega B, Pappa A, Panayiotidis MI, Franco R: Oxidative stress, redox signaling, and autophagy: cell death versus survival. Antioxid Redox Signal 2014;21:66-85. 